Revista de Derecho YACHAQ N. ${ }^{\circ} 12$

Centro de Investigación de los Estudiantes de Derecho (CIED)

Universidad Nacional de San Antonio Abad del Cusco

ISSN: 2707-1197 (en linea)

ISSN: 1817-597X (impresa)

Fecha de recepción: 24/10/2020

Fecha de aceptación: 08/01/2021

[pp. 39-51]

\title{
Entre dos sistemas jurídicos: análisis del conflicto de Bagua con base en la antropología jurídica
}

\author{
Between two legal systems: Bagua conflict analysis \\ based on legal anthropology
}

\author{
Carlos Andrés Loayza Ormachea ${ }^{[*]}$
}

«Si uno juzga al Perú por sus normas, uno pensaría que se encuentra en Suiza»

Carlos Ramos Núñez

\begin{abstract}
Resumen: el conflicto de Bagua nos demostró que al Perú le falta un largo camino por recorrer si quiere considerarse como una sociedad abierta a la pluriculturalidad. Esto pasa también por reconocer las diversas manifestaciones jurídicas que existen en el Derecho desde un enfoque basado en ideas del pluralismo jurídico. En este artículo, el autor analiza las ideas evolucionistas y las asocia a actores políticos como Alan García o Mercedes Aráoz. En segundo lugar, analiza la relación que se creó entre las comunidades nativas Awajún-Wampís y la globalización buscando la defensa de sus derechos frente al Estado; y, finalmente, presenta la relación entre el sistema jurídico del Estado y el de los AwajúnWampís con base en los conceptos del pluralismo jurídico.
\end{abstract}

Palabras clave: pluralismo jurídico; evolucionismo; Bagua; Antropología jurídica; pluriculturalidad.

Abstract: the Bagua conflict taught us that Peru has a long way to go if it wants to consider itself as open to multiculturalism. This also has to see with recognizing the multiple legal demonstrations that Law has from a point of view based of legal pluralism ideas. In this article, the author analyses the ideas of evolutionism and associates them with political actors as Alan Garcia or Mercedes Araoz. In second place, he analyses the relationship that was created between the Awajun-Wampis native communities and the globalization while looking for the defense of their rights against the State; and finally shows the relationship between the legal system of the State and the one of the Awajun-Wampís based on the legal pluralism concepts.

Key Words: legal Pluralism; Evolutionism; Bagua; Legal Anthropology; Multiculturalism.

[*] Alumno del octavo ciclo de la Facultad de Derecho de la Pontificia Universidad Católica del Perú. Asistente de docencia del curso Derechos Fundamentales e Interpretación Constitucional (Derecho Constitucional 2) en la Facultad de Derecho de la Pontificia Universidad Católica del Perú. Contacto: cloayzaorma@gmail.com 


\section{INTRODUCCIÓN}

No cabe duda que los eventos de Bagua, en el año 2009, han quedado entre los más trascendentes de la historia reciente del Perú. En torno a las protestas contra la explotación petrolera y el Decreto Legislativo que autorizaba al Estado a talar indiscriminadamente los bosques amazónicos, según la posición de las comunidades nativas, hubo un saldo difícil de ignorar: 33 muertos y más de 200 heridos. 10 indígenas y 23 policías perdieron la vida alrededor de estas protestas que, para muchos, sentaron un hito importante en el segundo gobierno del expresidente Alan García. Si bien es cierto que podemos estudiar los hechos de Bagua desde muchos puntos de vista, el objetivo del presente trabajo será el de analizarlos desde un punto de vista jurídico-antropológico y responder a la interrogante de por qué sucedieron. A través de las herramientas de la antropología jurídica, buscaré explicar cuál fue la importancia de las relaciones jurídicas entre el Estado y las comunidades nativas de la zona de Bagua para que se entienda desde ese plano qué fue lo que pasó.

Para empezar a hacer un trabajo de esta naturaleza, es necesario, antes que nada, despojarnos de prejuicios e ideas que podamos tener sobre ambos grupos sociales. Cada uno de nosotros puede tener una opinión acerca de lo que pasó en Bagua, y es completamente normal tenerla, pero para hacer $-\mathrm{y}$ leer - un trabajo con un enfoque antropológico se debe buscar la mayor imparcialidad posible. Usar cánones morales o jurídicos para sancionar las acciones de Alberto Pizango, Alan García y demás actores involucrados en los hechos no es labor de la antropología jurídica. Eso podríamos dejarlo a otras ramas del Derecho, cuya labor será la de - en caso sea necesario- castigar a los culpables y juzgar sus acciones. Lo que me interesará profundizar en este caso, a través de la información disponible en los medios digitales, audiovisuales y en la doctrina, es cómo la posición de las comunidades amazónicas y su cosmovisión se relacionó con el Derecho propuesto por el Estado a través de sus representantes.

\section{DESDE DARWIN HASTA MAÚRTUA: EL EVOLU- CIONISMO Y EL DERECHO}

Antes que nada, es necesario hacer una breve introducción a las teorías evolucionistas y su origen histórico. Estas se remontan, principalmente, a las ideas darwinianas de la evolución y selección natural. Darwin plantea entre sus teorías la idea de la supervivencia del más fuerte y apto como una forma de vida a la que todo ser viviente debe adaptarse si quiere mantenerse en la tierra. Estos planteamientos fueron tomados y adaptados para los seres humanos a través del darwinismo social y el determinismo biológico, posiciones que «dejan abierta la posibilidad de que ciertas razas o especies [humanas], sometidas a condiciones ambientales especialmente desfavorables — como algunas de las tribus 'salvajes [...]'se hubieran visto abocadas a procesos de estancamiento e incluso de degeneración relativa» (Sánchez, 2008, pp. 109-110). Lo que buscaba demostrar el darwinismo social es que las comunidades occidentales estarían en una posición de poder sobre las comunidades ajenas al orden europeo, pues estas se habrían desarrollado en condiciones ambientales, sociales y culturales que les permitirían un desarrollo intelectual más avanzado. Por lo tanto, los occidentales estarían en la obligación moral de «adoctrinar» a los salvajes y sacarlos de la barbarie y del retraso en el cual viven. Para Rubén García (2007), las concepciones sobre grupos sociales ajenos suelen estar basadas en rasgos distintivos generalmente prejuiciosos; como, por ejemplo, que los judíos huelen mal, que los alemanes son ebrios, que los africanos no piensan, que los indígenas son manipulables, etc. (p. 106).

Como era de esperarse, estas teorías también calaron en el Derecho y en las leyes que eran emitidas en ese entonces. En ese sentido, podemos distinguir a dos de los principales evolucionistas de la época: Lewis Morgan y Edward Tylor. El primero de ellos buscó sustentar cómo es que la sociedad ha ido avanzando culturalmente, económicamente, religio- 
samente e, incluso, en formas de gobierno y derechos propios de un ordenamiento jurídico desde un enfoque plenamente 'occidentalizado'. Para justificar su teoría, dividió en tres los estadios que todas las sociedades pasan en su proceso de evolución: salvajismo, barbarie y civilización. Durante el salvajismo, las comunidades solo logran vivir gracias a la recolección de alimentos de entorno natural cercano, la caza de animales y el fuego. Se encuentran aún en un estadio muy básico de la escala social, donde se les asemeja con los primeros habitantes de la tierra. Es también por el hecho de que consideran que estas culturas se encuentran más cerca del mono que del ser humano que le dan un aspecto de temible y bárbaro, completamente opuestos a todo lo que tenga que ver con la palabra desarrollo. En el siguiente estadio -la barbarie-, Morgan considera a aquellas comunidades que ya conocen técnicas agrarias, armas básicas de defensa como el arco y la flecha o incluso la fundición del hierro y su uso (Marrero, 2020, p. 324). Estas sociedades ya están un poco más cerca de ser civilizadas, por lo que se les tiene mayor consideración y menor dureza que a las etnias salvajes, en especial en la normatividad aplicable para ellos, como ya profundizaremos más adelante. Finalmente, el estadio máximo es el de la civilización, donde ya existe una organización más compleja, una sociedad urbanizada y habitantes que saben leer, escribir y comprender indicaciones. Morgan dice que antes de haber llegado a este último estadio las sociedades han debido pasar por todo el proceso de salvajismo y barbarie que les ha servido como experiencia en su progreso.

El segundo, Edward Tylor, sigue una línea muy parecida a la de Morgan, solo que con algunas particularidades. El autor parte de la idea - al igual que Morgan — de que el salvaje es aquel que se encuentra dentro del ámbito de la supervivencia, atascado dentro de una realidad de la que solo el sujeto occidental lo puede sacar; pues, al ya haber salido de esta etapa, estará en la obligación moral de guiar- lo hasta que salga. Según Apud (2011), Tylor consideraba que el salvaje en ese entonces era «una especie de 'fósil vivo', y la antropología un estudio 'arqueológico' de una cultura viva y muerta fosilizada en su desarrollo cognitivocultural». Surge, así, su teoría del «animismo», según la cual una forma de reconocer a estas culturas primitivas es su tendencia a creer en las almas, la magia, el espiritismo y el panteísmo. Aquellas sociedades que han superado con éxito esta etapa son aquellas sociedades a las que ya se les puede considerar civilizadas. El propio Tylor (1977), dice que:

«por un gran volumen de testimonios de la vida salvaje, de la bárbara y de la civilizada, las artes mágicas resultantes de esta errónea conducta de tomar un ideal por una relación real pueden ser claramente seguidas desde la cultura inferior de la cual han surgido hasta la cultura superior en la que actualmente se encuentran» (p. 122).

Por otro lado, el ser occidental, superior y civilizado, ha progresado hasta el punto en el que es monoteísta y no se deja convencer por ideas burdas acerca del alma y los dioses de estas culturas primitivas. El objetivo del occidental será, en ese sentido, adoctrinar al salvaje para que se logre la tan ansiada «cohesión social».

Así como en el ordenamiento social y jurídico occidental las teorías evolucionistas tuvieron gran influencia, el ordenamiento peruano no fue la excepción. Desde ese punto de vista podemos observar también planteamientos con alto sesgo evolucionista dentro de la doctrina jurídica peruana del siglo XIX y XX. Uno de los principales autores de esta corriente fue Víctor Maúrtua, diplomático peruano que estuvo dentro del grupo encargado de componer el código penal de 1924. En la redacción del código se puede ver repetidas veces cómo es que Maúrtua hace uso de los términos «salvajes», «indígenas semi-civilizados» y otras que, según Hurtado Pozo (1979), «reflejan su preocupación sobre la manera en que debían ser tratadas las personas que formasen parte 
de dichos grupos [...] inspirada por intereses de carácter altruista» (p. 84). Esta justificación coincide claramente con las ideas planteadas principalmente por Morgan, quien fácilmente podría encontrar justificable y correcto colocar fórmulas aleccionadoras dentro de un código penal cuyo objetivo sea el de educar e integrar a aquellos que están en el camino de la barbarie y el subdesarrollo. En ese sentido, según Ramos (2019), estas denominaciones de acuerdo a grado social y nivel de educación no tienen otro objetivo que el de convertir a todos aquellos «salvajes» 0 «semi-civilizados» en «ciudadanos occidentalizados» (párrafo 59). La forma de aleccionar o reeducar al indígena es a través de sanciones menos drásticas y con un régimen penal distinto, puesto que ellos no están capacitados para seguir una normativa penal estricta, como los civilizados. En el caso peruano, se consideraba como «civilizados» generalmente a los que viven en la costa o en las grandes urbes, mientras que los «semi-civilizados» y «salvajes» estaban esparcidos por toda la sierra y selva del país, respectivamente.

Si bien es cierto que el modelo evolucionista ha sido dejado de lado en la antropología después de los trabajos de Malinowski, muchas de sus ideas aún se mantienen presentes en los discursos políticos. Un ejemplo de esta presencia del evolucionismo en nuestro país es fácilmente reconocible en los discursos del expresidente Alan García y la exministra de Comercio Exterior y Turismo Mercedes Aráoz, ambos miembros del Poder Ejecutivo durante el desarrollo los conflictos del Baguazo.

\section{García, Aráoz y el Evolucionismo}

Se podría considerar que, entre los dos, el caso de Alan García es el más notorio. Fue a través de su discurso del 'Perro del Hortelano' — serie de tres artículos publicados en el diario El Comercio-y de declaraciones en medios y en actos oficiales que García demostró su posición evolucionista. Así, en «El síndrome del perro del hortelano», considera implícitamente que los ciudadanos amazónicos que se opo- nen a la extracción de petróleo lo hacen por una patraña creada desde tiempos del virrey Toledo, quien los engañó diciendo que sus tierras eran objetos sagrados y, además, explica que es ese mismo «engañado» quien no permite al Perú ser un país del primer mundo (Alan García, 2007a, pp. 1-4). En la segunda edición, García se atreve a dar una «receta» para acabar con este síndrome, donde propone abrir a la inversión pública todas las áreas «ociosas» que tiene el país, áreas atrapadas por «ciudadanos de segunda clase y sin iniciativa» condenados a mantenerse como tal si es que él y su gobierno no los apoyaban (Alan García, 2007b, pp. 7-8). Finalmente, en su tercera edición, el expresidente acusa al perro del hortelano de ser aquel que impide que los demás puedan salir de la pobreza y que él y su gobierno son los que van a guiar al Perú a ese primer mundo tan anhelado (Alan García, 2008, pp. 11-14). En estos tres discursos, se observa una intención de ponerse a sí mismo y a su gobierno como aquellos que van a sacar a los «bárbaros» de ese estado de desconocimiento y llevarles el progreso occidental que ellos necesitan para dejar de ser «primitivos» que lo único que hacen es evitar que la clase urbana del país progrese.

En armonía con los conceptos esgrimidos en sus artículos, García muchas veces se refirió en actos públicos y entrevistas al obstáculo que los pueblos indígenas suponían para el progreso del gobierno. El expresidente, en una entrevista, se refiere de esta forma a las comunidades nativas y sus creencias religiosas:

«...ideologías absurdas, panteístas, que creen que las paredes son dioses, que el aire es dios todavía. Volver a estas fórmulas primitivas de religiosidad donde se dice 'no toques ese cerro porque es un apu', 'no toques esos peces porque son criaturas de dios', 'no me toques esta zona que es un santuario'. Uno se pregunta: santuario de qué, ¿no? Un santuario porque ahí están las almas de los antepasados. Oiga, las almas de los antepasados están en el paraíso seguramente, no están allí»» (Vílchez, 2014). 
Estas declaraciones se ciñen claramente a lo que Tylor llamaba «animismo». Se degrada a aquellos que creen en una pluralidad de dioses, en la magia y en la sacralización de espacios físicos y se los pone al nivel del salvajismo. Desde esa visión, García busca convencer que su vía occidental y su creencia monoteísta y católica son superiores a la ideología absurda de los nativos.

En otro acto de gobierno posterior a los hechos del 5 de junio, García vuelve a referirse a las comunidades nativas con términos propios de las teorías de Morgan e, incluso, de los postulados de Maúrtua. García dice que «ese país mayoritario y moderno que buscamos [es el] que tiene que oponerse a fórmulas de salvajismo y de barbarie que [hoy] vuelven a aparecer...» (Vílchez, 2014). Claramente, García opone estas fórmulas de «retroceso» histórico y pone frente a ellas un modelo occidental de desarrollo que es - supuestamente- el que la mayoría quiere y, por tanto, el que la mayoría debe tener. No debería importar si ello va en contra de lo que podrían llegar a pensar los nativos, puesto que ellos no importan en las decisiones de gobierno al asumir que son seres inferiores. Además, en esa misma vía, García considera que los nativos que protestan contra los decretos no merecen ser llamados «ciudadanos de primera clase» por su oposición al desarrollo (Bradenburg, 2016), y se pone a sí mismo y al pueblo «civilizado» y «de primera clase» como los responsables de hacer que los nativos cambien su mentalidad. Para lograr este progreso, es necesario enseñar a los «salvajes» a través de la mano dura que solo el Estado debe aplicar. Esto se ve reflejado en las acciones empleadas por el gobierno de García para contener y repeler el levantamiento de los nativos. Según Guido Lombardi —presidente de la comisión investigadora de los hechos de Bagua-, a pesar de que los nativos habrían acordado retirarse de la Curva del Diablo, el gobierno había decidido que no se fueran sin «Su buena lección» (Vílchez, 2014). Esto difiere en parte de lo que dice Maúrtua, pues en este caso el Estado, para él, debería castigar a los nativos para que aprendan a no transgredir y para ceñirse a la ley, no perdonarlos y ser compasivos con él. En otras palabras, ser paternalista con el inválido.

El problema de Bagua surgió porque García y su gobierno sacaron una serie de decretos legislativos que vulnerarían la propiedad de las tierras nativas. Si estos no se daban — según el gobierno- el Tratado de Libre Comercio recién firmado con Estados Unidos se perdería. Esta posición fue transmitida principalmente por Mercedes Aráoz, en ese momento ministra de Comercio Exterior y Turismo y, por tanto, la encargada de mantener en buen rumbo el tratado. Cuando Aráoz se refiere a los nativos, lo hace como los sujetos a los que debe explicárseles las cosas y donde ella es quien conoce y guía sus necesidades. En esa misma entrevista, Aráoz (2009), se muestra a sí misma como la persona capacitada para designar a los líderes de las propias comunidades nativas y se siente capaz hasta de decidir en vez de ellos. Actitudes como estas demuestran una idea de intentar «civilizar» a los «salvajes» — los manifestantes de Bagua- y de librarlos de sujetos que estarían pervirtiendo su forma de pensar inocente. Como ella tiene la idea de que los nativos son fácilmente manipulables, tiene el concepto firme de que ellos reclaman no por convicción, sino porque alguien más los pervirtió. Entonces, ella está en la obligación moral de salvarlos de esta cruel manipulación. La mejor forma de salvarlos de esta barbarie era dictando decretos especiales para ellos, exclusivos para su caso y que el gobierno no les explicó porque asumió que no los entenderían.

\section{COMUNIDADES NATIVAS: ENTRE EL DERECHO Y LA GLOBALIZACIÓN}

Alrededor de todo el conflicto de Bagua, hubo un hecho que llamó mucho la atención: el uso que las comunidades nativas hacían tanto de su propio Derecho como del Derecho Internacional y de sus Derechos Fundamentales reconocidos en la Constitución. Este hecho 
podría parecer extraño a primera vista, pero no lo es en ningún sentido, pues las comunidades nativas también han sido parte de los procesos de globalización. Generalmente se nos ha mostrado una imagen ajena del habitante selvático, principalmente a través de los medios de comunicación, quienes han contribuido en la creación del prejuicio del poblador amazónico como apartado completamente de la sociedad moderna, cuando no es así. Muchas de las consecuencias de la globalización han repercutido en ellos tanto de forma positiva como de forma negativa.

De forma positiva, las comunidades nativas han empezado a tener acceso al mundo jurídico internacional y a conocer de mejor manera sus derechos ante el Estado. En ese sentido, quienes han apoyado sobremanera a lograr este objetivo han sido sujetos como Alberto Pizango, quien fácilmente podría encajar en el concepto que Goodale maneja de los «superempowered individuals» (o individuos superpoderosos). Para el autor, hay sujetos dentro de las comunidades nativas que han logrado introducir e inculcar los conceptos relativos a derechos humanos e indígenas a través de su estatus de «filósofos morales» (2000, p. 60). En el documental «When Two Worlds Collide» (Bradenburg, 2016), se ve claramente cómo sujetos como Pizango, líder de la Asociación Interétnica de Desarrollo de la Selva Peruana (Aidesep), han aprovechado su estatus político dentro de la comunidad para que los nativos aprendan más acerca de sus derechos y que se den cuenta del daño que están haciendo a su entorno.

El impacto de esta filosofía es muy notorio: con solo ver las entrevistas que se hace a los nativos, tanto en este como en otros docu- mentales, estos demuestran lo interiorizados que han quedado muchos de estos derechos en su mentalidad. Ellos son completamente conscientes de que son sujetos de derecho en el ordenamiento jurídico nacional e internacional, y son conscientes de las ventajas y responsabilidades que ello supone. Los nativos no han ido a protestar sin una razón consistente a la Curva del Diablo y a la Estación $\mathrm{N} .^{\circ} 6$, sino que lo han hecho porque creen firmemente que tienen la razón y que con estos decretos legislativos muchos de sus derechos internacionalmente reconocidos han sido vulnerados, especialmente aquellos referidos al Convenio 169 de la OIT ${ }^{[1]}$, el cual es citado recurrentemente por los líderes nativos. Efectivamente, como dice Goodale, sujetos como Pizango «han sido luz para el movimiento de las ideas legales [...] y del inicio de la transformación de las nuevas ideologías locales» (2000, p. 65) (traducción propia).

Esta nueva apertura de las comunidades nativas a la globalización y al mundo exterior ha generado como consecuencia que el hacer una etnografía sea más difícil. Hoy en día ya no estamos ante la misma realidad social que Malinowski, quien nos invitaba a quedarnos en el mismo lugar en el trabajo antropológico, pues dentro de él encontraríamos toda la información necesaria. Con la (des)centralización, esto ha cambiado, puesto que el antropólogo, al hacer campo, se ve obligado a ir más allá de los límites de la comunidad que se ha propuesto estudiar. Al respecto, Goodale propone la teoría de «seguir las ideas» (o follow the ideas) que nos explican que el campo ya no tiene un significado geográfico concreto: hoy en día, ese espacio geográfico se ha ampliado exponencialmente a una gran red de ideas que ya no se encuentran geográ-

[1] El Convenio 169 de la Organización Internacional del Trabajo (OIT), sobre pueblos indígenas y tribales en países independientes fue promulgado en junio de 1989 y suscrito por el Perú en diciembre de 1993. Este convenio es de extrema importancia puesto que en él se garantizan los principales derechos que los pueblos indígenas y las comunidades nativas tienen ante el Estado y la sociedad en general tanto sobre sus tierras como sobre su cultura en general. 
ficamente en un solo lugar, sino que incluso te pueden llevar a sitios inesperados (2000, p. 64). A esta teoría se le puede complementar lo planteado por Merry, quien plantea su teoría de la «etnografía sin territorio» (o deterritorialized ethnography), según la cual ni lo local puede ser entendido sin observar lo global; ni tampoco lo global puede ser entendido lejos de lo local (2000, p. 129). Este hecho es visto con claridad en el documental When Two Worlds Collide (2016), donde se ve cómo el panorama va cambiando constantemente: por momentos es presentado desde las propias comunidades y, por otros momentos, desde Lima, donde tanto el Congreso, los especialistas acerca del tema e incluso la sede de la Aidesep se encuentran. Lo local, que en este caso son las comunidades nativas de Bagua, no debe ser entendido de forma ajena a lo global, que vendría a ser tanto el Estado y Lima, la capital. Restringirnos a estudiar el Baguazo solo desde las comunidades cercanas a Bagua sería un error.

Por otro lado, mencioné que la globalización también puede ser vista desde un sentido negativo para las comunidades nativas. El ingreso de la globalización en sus tierras ha traído consigo muchos problemas, que incluyen la amplia depredación forestal y la extracción minera desmedida e irresponsable. Legalmente, ellos están protegidos al respecto por el convenio 169 de la Organización Internacional del Trabajo, el que les garantiza el derecho a que, si es que en algún momento se va a hacer algún proyecto minero, petrolero o similares que vayan a impactar directamente en su cotidianeidad sean consultados y exista una autorización expresa de su parte ${ }^{[2]}$. Por otro lado, la Declaración sobre los Derechos de los Pueblos Indígenas de las Naciones Unidas que también es mencionada dentro del conglomerado de normas importantes en el documental, se refiere a la participación activa que los pueblos indígenas deben tener en aquellas decisiones que afecten directamente sus vidas. Aun así, los impulsos globalizadores han llegado con tanta fuerza que constantemente la minería y la gran empresa han pasado por alto sus derechos, con el aval del gobierno de turno en muchos casos. Es por estas razones que también los nativos se han levantado contra el Estado, como indagaremos más adelante: se ha vulnerado gran parte de sus costumbres, tradiciones y concepciones acerca de su entorno social y cultural; por lo que, al sentirse retados, han respondido. Y con razón.

\section{EL PLURALISMO JURÍDICO: RELACIÓN ENTRE EL DERECHO ESTATAL Y EL DERECHO DE LAS COMUNIDADES NATIVAS}

Después de haber profundizado en las posiciones de ambas partes y en las concepciones y demandas que el uno tiene del otro, ahora sí podemos adentrarnos más en la importancia del pluralismo jurídico para la resolución de esta clase de conflictos y de la importancia que tiene el negociar entre ambos ordenamientos jurídicos horizontalmente y no en verticalidad.

Antes de analizar este fenómeno, es necesario conceptualizar qué es el pluralismo jurídico. Este es un concepto muy amplio sobre el que ha existido grandes debates en la doctrina. No es el propósito de este artículo ahondar en este debate, pero sí considero necesario para reforzar esta argumentación presentar al menos las posiciones de dos autores: Pospisil y Moore.

En primer lugar, Leopold Pospisil, profesor de la universidad de Yale, propuso la teoría

[2] Este derecho es parte de lo reconocido actualmente por la ley 29785 «Ley del Derecho a la Consulta Previa» en la que se prevén procedimientos que el Estado y los particulares deberán seguir para la inversión en tierras indígenas y nativas. A pesar del importante avance que esta ley representa, esta sigue presentando muchos problemas (léase: Debate en torno a la Ley de Consulta Previa (Peña, A. Huapaya, R. \& Rodrigo, L.), lus et Veritas (43), pp. 402-416). 
del derecho como una herramienta de control social aplicada en forma universal y que involucra una relación tanto obligatoria como sancionatoria (1974, p. 95). Lo que busca plantear es que el derecho debe ser considerado como una norma con la capacidad de mantenerse con el tiempo, de sancionar y de obligar a los miembros de una sociedad a actuar de cierta manera. A pesar de ello, Pospisil es consciente de la existencia de lo que él llama «subgrupos», a los cuales la gran parte pertenecemos. Estos subgrupos, en ese sentido, deben tener cuatro características específicas para que puedan ser considerados como sistemas legales: autoridad, capacidad de sanción, relaciones obligacionales e intención de aplicación universal (Guevara, 2009a, p. 34). Si es que un grupo cumple con estas cuatro características, entonces puede entrar a la denominación de Derecho. Lo que genera esta amplitud es la capacidad de que un mismo ser humano pueda ser parte de varios sistemas legales a la vez y que esté también en la capacidad de cumplirlos todos sin que conlleve un problema. Eso sí, el cumplimiento será considerado el adecuado siempre y cuando asuman e interioricen que esas normas son parte de su esquema moral; pues, si no, serían simples normas muertas (Pospisil, 1958, 248). Además, Pospisil se ha dedicado a criticar duramente la idea de que el Estado es la fuente más grande de control social. Él considera que no es así, puesto que cada subgrupo social está en la capacidad de generar su propio sistema legal en tanto es parte de la naturaleza de su propia unidad social (Pospisil, 1974, p. 125). Tanto es así que también ha considerado que la llegada del Estado a estos subgrupos puede causar miedo a un poder más grande antes que la creencia de que se están siguiendo las prerrogativas acordes a sus creencias, lo que termina por generar una mera conformidad superficial (Pospisil, 1981, p. 101).

En segundo lugar, tenemos la teoría de Sally Moore, profesora de la universidad de Harvard, quien revoluciona completamente los estudios del pluralismo jurídico al rechazar de plano las ideas que muestran al Derecho como un mecanismo de ingeniería social capaz de legitimar posiciones de poder (Guevara, 2009a, p. 35). Muchas veces se ha pensado que el Derecho es capaz de moldear la realidad y modificarla a su gusto, cuando esto no es así: es el Derecho el que está en la obligación de adaptarse a las diferentes formas de vida que existe en la sociedad. Así, Moore propone la teoría de las áreas sociales semi autónomas (semi-autonomous social fields), según la cual los subgrupos distintos al Estado que conviven en la sociedad sí son capaces de generar normas vinculantes para sus miembros puesto que cada uno de estos subgrupos tiene una propia forma de vida que poco a poco ha sido interiorizada por sus miembros (1973, p. 722). Cada uno de estos espacios sociales que han surgido fuera del Estado tienen un cierto grado de autonomía dentro de su realidad, por lo que se debe considerar la existencia no de una sino de varias fuentes de regulación social (Guevara, 2009a, p. 36). Estas diversas fuentes de regulación social ayudan a los sujetos a identificarse ante la sociedad como partes de un grupo, lo que también ayuda en la construcción de su propia subjetividad. Finalmente, estas áreas sociales semi-autónomas no viven aisladas entre sí. Moore explica que estas funcionan como «cadenas»; es decir, están unidas entre sí en tanto las personas que forman parte de cada subgrupo pueden formar parte de diversos subgrupos a la vez, lo que termina formando cadenas unidas entre sí (1973, p. 722).

La autora sigue la línea de Pospisil en el sentido de reconocer la existencia de diversas formas de regulación que los grupos sociales en particular pueden ejercer dentro de su entorno. Más adelante, Moore deslinda de Pospisil y sus características específicas y propone la «reglamentación» si es que queremos hablar de grupos sociales distintos al Estado para reservar a este último el término Derecho de manera exclusiva. Además, Moore enfatiza en 
el término de semi-autonomía para referirse a los espacios sociales: estos espacios son capaces de generar normas y costumbres, pero también son vulnerables a otras fuerzas de contextos mayores, las que vienen determinadas por su capacidad de adaptación al cambio (Guevara, 2009a, p. 37).

Lo que encontramos en este conflicto es a un Estado que cree en lo que Moore ha refutado. A través de las acciones ya estudiadas de miembros del Estado como Alan García se ve que lo que busca el Estado es cambiar una realidad social a través de normas sociales y de acciones que busquen «dar una lección» a los nativos, como fueron los enfrentamientos de la Curva del Diablo. Por otro lado, vemos a los grupos nativos como comunidades con reglas acerca de cómo debe ser el mundo que los rodea, centrado principalmente en el cuidado de su medio ambiente $y$, en especial, del rol de las plantas como sus guardianes y guías (Centro Takiwasi, 2018). La investigación de Regan también es útil para entender un poco más a fondo la tradición de los Awajún y Wampís. Menciona que es en la naturaleza donde ellos tienen un encuentro personal con seres de otra clase, además de pregonar siempre el uso cauto de los recursos ambientales (2010, p. 24). Para las comunidades Awajún y Wampís, es a través de la naturaleza que ellos van a poder encontrarse a sí mismos y a su forma de vida, por lo que destruir sus tierras sería como destrozar a una parte de su personalidad. Es por estas razones que estos pueblos indígenas han llegado hasta el extremo de dar su propia vida para defender sus tierras y sus costumbres.

Aun así, verlos solo desde este punto de vista exclusivamente sería un error. Sería importante ir más allá y darnos cuenta de que fuerzas externas han entrado y han intervenido en el sistema reglamentario de estas comunidades. Tanto los tratados internacionales de derechos humanos, los convenios sobre derechos indígenas y el derecho estatal han sido introducidos a la tradición nativa, hasta tal punto que han interiorizado estas normas y hoy en día las usan para defender su causa. Tal y como explicó Moore: son vulnerables a las normas dictadas por fuerzas superiores, pero también pueden cambiar su propia normativa.

El gran problema surge cuando el gobierno cree que puede crear normas para cambiar la realidad y que ellos en el Derecho tienen una herramienta divina capaz de cambiar todo aquello que les parezca incorrecto. Lo que no han visto es que hay un sistema jurídico que se resiste a que aquellas normas sean cambiadas, puesto que estas tienen un valor sagrado para ellos. Valor que el Gobierno históricamente se ha negado a aceptar. Lo que cree el Gobierno es que lo único que hacen los nativos es ir contra el progreso que ellos tanto anhelan, aunque el progreso signifique vulnerar las costumbres y creencias de un grupo considerado como inferior, manipulable y ante el que tienen una obligación moral de adoctrinamiento. Entonces, a través de todo lo expuesto hasta el momento, vemos un tema que sí es de sumo interés para la antropología jurídica y, más aún, para el pluralismo jurídico. Tenemos la interacción entre dos sistemas normativos: uno que busca imponer su sistema a través de normas con pretensión de obligatoriedad y otro que busca hacer respetar su sistema jurídico tradicional. Para cumplir con este objetivo, cada parte hace uso de sus propias herramientas: el Estado, de las fuerzas policiales y de la capacidad normativa del Ejecutivo, y las comunidades nativas del derecho internacional y de su propio derecho. En su filosofía está inscrita la idea de que, si los débiles se alían y organizan correctamente, podrán vencer al grande y poderoso (Regan, 2010, p. 31). El grupo Awajún y Wampís, como era de esperarse, se resistió al cambio impuesto por el Gobierno y ha hecho uso de la fuerza en cuanto ha visto que el problema crecía: tomaron la Estación N. ${ }^{\circ} 6$ cuando se enteraron de la noticia, luego desmentida, de que había una matanza en la Cur- 
va del Diablo donde uno de sus líderes, Santiago Manuin, había fallecido, lo que los exacerbó mucho más (Vílchez, 2014) ${ }^{[3]}$.

Cuando existen esta clase de conflictos lo ideal es entablar una negociación cuyo objetivo sea llegar a un punto intermedio en el que ambos sistemas cedan parte de su posición para llegar a una solución. Sin embargo, no considero que el proceso de negociación y solución del conflicto de Bagua fuera el adecuado. La posición del gobierno ante la negociación fue equivocada y grandilocuente, buscando siempre resaltar su superioridad resaltando cada vez que podía las ventajas de la modernidad por sobre el «atraso» que la posición e incluso la existencia de las comunidades nativas suponía. Esto, según Guevara, va muy acorde a una posición casi usual del Estado por sobre la diversidad, quien ha buscado, a través de un "derecho moderno" centralizado, cancelar esta diversidad con leyes y más leyes de pretendida aplicación universal (2009b, pp. 6566). Manejar un país con un territorio tan grande y diverso es ya de por sí complicado, pero es mucho más complicado aún si es que el gobierno no acepta la diversidad y sigue pensando que imponerse es la mejor salida. Incluso, en el informe presentado por Guido Lombardi (2010) al Congreso ${ }^{[4]}$, se ve que desde el año 2008 es que la Aidesep intentó negociar con el gobierno para llegar a una solución pacífica, pero el gobierno no comprendió que el origen de las protestas estaba en los decretos legislativos (p. 171). Más adelante, se demostró la nula disposición de la ministra Aráoz a discutir los proyectos de decretos legislativos presentados con la comisión multisectorial del Congreso para buscar soluciones (Lombardi, 2010, p. 123). Se demostró, además, que a pesar de que los pueblos indígenas ya llevaban más de ocho meses en conflicto, el Ejecutivo no se atrevió a crear una mesa de diálogo, la que fue creada solo después de la presión hecha por la Defensoría del Pueblo (Lombardi, 2010, p. 174). Además, gestos políticos como la postergación del debate parlamentario acerca de los decretos legislativos por parte de la bancada oficialista no hicieron más que demostrar la falta de voluntad política del gobierno de dialogar y solucionar. Toda esta seguidilla de actos y en especial los eventos de la Curva del Diablo llevaron a una ruptura irreconciliable de las negociaciones entre ambas partes.

Revisar el informe Lombardi da luces de por qué es que las negociaciones se cayeron e incluso empeoraron mucho más el conflicto en la Amazonía. Se dan cuatro razones que cito a continuación:

«1.- La incapacidad del Poder Ejecutivo para atender las demandas principales de las Comunidades Indígenas, que ocultó al hacer creer que las mesas conformadas darían solución al conflicto.

2.- La falta de voluntad de formalizar dichas mesas de diálogo, por [...] las escasas reuniones que se realizan con las instituciones de representación de las co-

[3] Es importante resaltar que, para los Awajún y Wampís, la muerte de uno de sus apus es como la muerte de su propio padre. Son ellos quienes los guían tanto moral como espiritualmente. El rumor de la muerte de Manuin, entre otros, con toda razón fue parte de lo que enervó a los nativos y los llevó a asesinar a 10 policías en la Estación 6.

[4] El informe de la comisión investigadora de los hechos de Bagua, liderada por el excongresista Guido Lombardi, llegó a conclusiones muy fuertes respecto a los hechos de Bagua, las que no fueron reveladas durante mucho tiempo debido a la resistencia por parte del Congreso de la República, liderado en ese entonces por fuerzas afines al expresidente García. Solo fueron mostrados informes hechos por la entonces ministra del interior Mercedes Cabanillas en los que se restaba casi por completo la responsabilidad del Estado en los hechos de Bagua. El informe de la comisión Lombardi recién fue abierto a la opinión pública el año 2011 cuando el tema ya se había enfriado. 
munidades indígenas antes y después de la creación de las mesas.

3.- La falta de conocimiento en relación a las formas de representación política que manejan las comunidades indígenas, y el papel de sus dirigentes amazónicos [...]

4.- El desconocimiento de las instituciones políticas amazónicas, sus diferencias, disputas y nivel de representatividad...» (2010, p. 175).

Estas cuatro razones no hacen más que demostrar la falta de conocimiento que tiene el gobierno sobre la realidad de estas culturas, lo que también engloba el desconocimiento sobre sus costumbres jurídicas. El saber que los Awajún y Wampís no fueron al paro buscando un enfrentamiento sino buscando expresar su preocupación por el futuro de sus comunidades probablemente hubiera evitado que el conflicto creciera (Regan, 2010, p. 32). Desconocer la realidad de estas culturas llevó al Estado a frustrar las mesas de negociación y a empeorar el conflicto. Un enfoque pluralista, en el que se comprendan las particularidades y características del sistema Awajún y Wampís, hubiera sido útil para encontrar mejores soluciones y evitar las grandes pérdidas que el Baguazo ocasionó.

Aun así, a pesar de la gran responsabilidad política que ya tiene, dar toda la responsabilidad al gobierno de García sobre el conflicto de Bagua sería falaz. Como indica Guevara (2009b), este es un problema estructural que proviene incluso de los inicios de nuestra vida republicana, donde se daban normas «dirigidas a regular paisajes humanos y geográficos por demás inasibles para el centralismo limeño...» (p. 71). El objetivo histórico del Estado no ha sido comprender, sino el de colonizar. Alan García es solo uno más de los partícipes de esta maraña de problemas que ha tenido el Estado para comprender las otras realidades que un país tan diverso como el Perú presenta. Eso sí, ello no quiere decir que las acciones que su gobierno tomó para contener y comprender el conflicto no fueron para nada correctas.

\section{CONCLUSIONES}

En conclusión, el gobierno de Alan García hizo uso de conceptos evolucionistas para justificar la inversión petrolera y minera dentro de los territorios Awajún y Wampís. Estas fórmulas vienen muy relacionadas con los postulados de Morgan, Tylor y Maurtúa. Diversas declaraciones en la prensa y en actos públicos demuestran esta posición tomada tanto por García y su ministra Mercedes Aráoz. Por otro lado, las comunidades nativas han adoptado partes del derecho internacional para sustentar la defensa de sus territorios. Esta integración se produjo de acuerdo a lo postulado por Goodale y Merry, quienes previeron que en nuestra realidad globalizada los derechos humanos tendrían un papel más importante en la defensa de estas comunidades. Por otro lado, se ve que esta situación sí es de interés para el pluralismo jurídico puesto que dos sistemas jurídicos que han chocado entre sí deberán entenderse: el sistema del Estado y el sistema de las comunidades nativas. Al momento de negociar y ceder el gobierno cometió errores políticos que terminaron por empeorar el conflicto y a llevarlo hacia una escalada. Este desconocimiento y resistencia a aceptar la diversidad que tiene nuestro país nos ha llevado a muchos problemas históricamente, por lo que es imperativo cambiar la visión colonizadora que aún impera en el Estado.

Introduciendo ya un carácter un poco más subjetivo al análisis, planteo la siguiente pregunta: ¿qué hacer para cambiar esta realidad y dar un enfoque pluricultural al Estado? Para Guevara (2009b), cambiar esta realidad pasa por «forjar una nueva relación con la sociedad basada en el reconocimiento de la diversidad social y normativa» (p. 74). Generar este reconocimiento pasa por un cambio grande dentro del Estado en el que las instituciones y los gobernantes reconozcan la diversidad cultural y normativa que tiene nuestro país para evitar que se busque imponer un sistema normativo para todos por la fuerza. Esto también conlleva dejar de ver al Derecho como esta herramien- 
ta divina capaz de solucionarlo todo. Aceptar la diversidad nos ayudará a generar inclusión y crecimiento real, el que no necesariamente va de la mano con el crecimiento occidentalizado que se nos ha mostrado como el único posible. Respetar las diferencias y trabajar en un enfoque pluralista en el que ningún sistema jurídico es superior a otro debería ser una prioridad si queremos evitar otro Baguazo. Principalmente, entender - como indica el profesor Fernando de Trazegníes (1983) - que «el indígena no es un ser semi-civilizado sino civilizado de otra manera» (p. 150).

\section{REFERENCIAS}

Apud, I. (2011). Magia, ciencia y religión en Antropología Social: de Tylor a Levi-Strauss. Nómadas. Revista Crítica de Ciencias Sociales y Jurídicas. 30(2). https://www.redalyc.org/ pdf/181/18120143021.pdf

Araoz, M. (2009). Entrevista de César Hildebrandt a Mercedes Aráoz (ministra de Comercio Exterior y Turismo) [Entrevista]. RBC Televisión.

Bradenburg, H \& Orzel, M. (2016). When Two Worlds Collide [Documental]. Yachaywasi Films; Just Films.

Centro Takiwasi (2018). Entrevista con el Líder Awajún Santiago Manuin [Video]. YouTube. https://www.youtube.com/watch?v=_7xA nZd201s.

De Tragzenies, F. (1983). Informe a la Comisión Investigadora de los Sucesos de Uchuraccay. En Mario Vargas Llosa (Editor), Informe de la comisión investigadora de los sucesos de Uchuraccay (pp. 127-152). Fondo Editorial de la PUCP.

García, A. (2007a). El síndrome del perro del hortelano. El Comercio. https://indigenasdelperu. files.wordpress.com/2015/09/26539211-alangarcia-perez-y-el-perro-del-hortelano.pdf

García, A. (2007b). Receta para acabar con el perro del hortelano. El Comercio. https://indigenasdelperu.files.wordpress. com/2015/09/26539211-alan-garcia-perezy-el-perro-del-hortelano.pdf

García, A. (2008). El perro del hortelano contra el pobre. El Comercio. https://indigenasdelperu. files.wordpress.com/2015/09/26539211-alangarcia-perez-y-el-perro-del-hortelano.pdf

García, R. (2007). Derecho a la diferencia y combate a la discriminación. En Comisión de Derechos Humanos del Distrito Federal. Discriminación, Igualdad y Diferencia Política (pp. 97-136). https://www.corteidh.or.cr/ tablas/27899.pdf

Goodale, M. (2000). Legal Ethnography in an era of globalization: the arrival of Western Human Rights discourse to rural Bolivia. En June Starr y Mark Goodale. Practicing Ethnography in Law (pp. 50-71). Palgrave Macmillan.

Guevara, A. (2009a). Apuntes sobre el pluralismo legal. En Armando Guevara (Editor). Diversidad y complejidad legal. Aproximaciones a la Antropología e Historia del Derecho (pp. 29-60). Fondo Editorial de la Pontificia Universidad Católica del Perú.

Guevara, A. (2009b). Las causas estructurales de la pluralidad legal en el Perú. En Armando Guevara (Editor). Diversidad y complejidad legal. Aproximaciones a la Antropología e Historia del Derecho (pp. 61-77). Fondo Editorial de la Pontificia Universidad Católica del Perú.

Hurtado, J. (1979). La Ley «importada». Recepción del derecho penal en el Perú. CEDIS.

Lombardi, G. (2010). Informe de la Comisión Investigadora sobre los hechos acontecidos en la ciudad de Bagua, aledaños y otros, determinando responsabilidades a que haya lugar. Congreso de la República del Perú. http://www2.congreso.gob. pe/sicr/apoycomisiones/informes.nsf/e4f6 3a4ffbb4387005257807005e11d9/7a8837 c7c53cf00a05257728004f4338/\$FILE/INF. BAGUA(Lombardi1).pdf http://www2.congreso.gob.pe/Sicr/ApoyComisiones/infor- 
mes.nsf/fae19ad9f65c7e59052577fa005136 8c/7b19c6755642cfec05257800004e7b14/\$ FILE/INF.BAGUA(Lombardi2).pdf

Marrero, C. (2020). Acerca de Henry Lewis Morgan (1818-1891) y su obra 'Ancient Society'. Revista científica de la Asociación de Historia y Antropología de los Cuidados. 24(56), 322-326. http://dx.doi.org/10.14198/ cuid.2020.56

Merry, S. (2000). Crossing Boundaries: Ethnography in the Twenty-First Century. PoLAR. 23(2), 127-132.

Moore, S. (1973). Law and social change: The semi-autonomous social field as an appropriate subject of study. Law \& Society Review. 7(4), 719-746.

Pospisil, L. (1958). Kapauku Papuans and Their Law. New Haven, Published for the Dept. of Anthropology, Yale University.

Pospisil, L. (1974). Anthropology of Law. A Comparative Theory [Antropología Jurídica. Una teoría comparativa]. Harper and Row Publishers.
Pospisil, L. (1981). Modern and Traditional Administration of Justice in New Guinea. Journal of Legal Pluralism. 19, 93-116.

Ramos, C. (2019). La Ley Penal y el indio: de la Realidad del Discurso al Discurso de la Realidad». Forum historiae iuris. https://forhistiur. de/2019-03-ramos-nunez/

Regan, J. (2010). Los awajún y wampís contra el Estado: una reflexión sobre la antropología política. Investigaciones Sociales. 14(24), 1935. https://doi.org/10.15381/is.v14i24.7278

Sánchez, J.M. (2008). La biología humana como ideología: el racismo biológico y las estructuras simbólicas de dominación racial a fines del siglo XIX. Theoria. Revista de Teoría, Historia y Fundamentos de la Ciencia. 23(1), 107124. https://www.pdcnet.org/theoria/content/theoria_2008_0023_0001_0107_0124

Tylor, E. (1977). Cultura Primitiva. Editorial Ayuso.

Vílchez, F. (2014). La Espera, historias sobre el Baguazo [Documental]. Asociación Otra Mirada. https://www.youtube.com/ watch?v=ERUeH9mmvGM 